\title{
HIPÓTESE SOBRE A ORIGEM DA DEPRESSÃO PERIFÉRICA PAULISTA
}

\author{
Percy Corrêa VIEIRA *
}

\begin{abstract}
RESUMO
Propõe-se neste trabalho discutir evidências da existência de processo tectônico gerador da Depressão Periférica Paulista, representado pelo afundamento da borda nordeste da Bacia Sedimentar do Paraná, no Cenozóico e evidenciado pela seqüência dos eventos geológicos que afetaram o sudeste brasileiro.
\end{abstract}

\section{ABSTRACT}

It is proposed in this paper, a tectonic and erosive origin to the São Paulo State Peripheric Depression. This is recorded by all geologic events wich had place in the Brazilian southeast region.

\section{INTRODUÇÃO E OBJETIVO}

O desenvolvimento do "Projeto de Levantamento de Formações Geológicas de Superfície", que está em execução no Instituto Geológico, com o mapeamento da região nordeste da Bacia Sedimentar do Paraná no Estado de São Paulo (escala 1:50.000) levou o autor a concluir por uma origem tectônico-erosiva para a Depressão Periférica Paulista, sendo propósito deste trabalho expor tal assunto.

\section{MATERIAL E MÉTODOS}

A metodologia constituiu-se de:

a) interpretação aerofotogeológica e de imagens do Satélite Landsat, com base nas técnicas convencionais;

b) levantamento geológico de campo com uso das técnicas habituais;

c) estudo crítico das propostas de autores quanto à evolução tectônica do sudeste brasileiro.

\section{DISCUSSÃO E RESULTADOS}

\subsection{Generalidades}

SAAD (1977) propõe por hipótese um basculamento do embasamento do Supergrupo Tubarão na região nordeste do Estado, em contraposição à parte central aflorante. SANTOS (1979) afirma que a deposição deste Supergrupo deu-se sobre um embasamento irregular, identificando elementos tectônicos na margem norte da $\mathrm{Ba}-$ cia do Paraná. ABREU (1973) fala da presença de tectonismo na região, citando tectônica quebrante provavelmente paleozóica, com reativação associada ao magmatismo mesozóico.

BJORNBERG et alii (1968b) afirmam que o Rio Moji-Guaçu e outros seguem em longos trechos, orientações tectônicas e dizem que a tectônica moderna tem posição igual ao clima no controle das formas do terreno. BJORNBERG et alii (1968a) falam de pequenos blocos basculados e grandes superfícies cenozóicas adernadas em várias direções. BJORNBERG et alii (1971) sugerem que a fonte do Grupo Bauru fica-

Recebido para publicação em maio de 1983.

* Instituto Geológico - Caixa Postal 8772 - 01000 - São Paulo, SP, Brasil. 
ria numa faixa que se estende de Tatuí a Piraçununga. Admitem serem recentes as manifestações tectônicas responsáveis pelas alterações geológicas. Afirmam esses autores à pág. 174: "Acreditamos que a Depressão Periférica tenha se originado por atuação conjunta de fenômenos de tectônica rígida (grande número de pequenas fraturas cisalhantes, formando extensas zonas brechadas) e ação erosiva de uma drenagem subsequiente".

Vários autores têm sugerido uma origem tectônico-estrutural para as chamadas "cuestas" dessa região da Bacia do Paraná; destacam-se FULFARO et alii (1967), FULFARO \& SUGUIO (1968); MENDES \& FULFARO (1968), PENTEADO (1968), FULFARO (1971), RIBEIRO (1973), FULFARO (1974), PENTEADO (1976) e BRANDT NETO et alii (1981).

FULFARO (1971) admite que no Cretáceo final a Serra Geral não existia como feição estrutural e a drenagem fluía da borda leste para o centro da bacia. Então falhas começaram a ser reativadas e a drenagem passou a encontrar barreiras, sofrendo desorganização. Enchentes periódicas formaram os sedimentos chamados de modernos. As falhas, individualmente falando, são de pequeno rejeito (não maiores que dez metros), o que não causaria grande dificuldade para os rios cortarem a região. A soma dos rejeitos individuais entretanto é grande, chegando aos trezentos metros. Diz esse autor também que as zonas de alimentação dos derrames basálticos parecem localizar-se na periferia da bacia, região elevada, sendo que o atual topo da Serra Geral era região baixa.

\subsection{Caracterização da Depressão}

A Depressão Periférica Paulista tem início na região de Monte Santo de Minas, onde se apresenta estreita; sua largura média, entretanto, orça pelos cem quilômetros. Caracteriza-se como uma faixa deprimida entre as escarpas de diabásio e arenitobasálticas, que delimitam sua borda ocidental e o Planalto Cristalino Atlântico, que delimita sua borda oriental. Sua ocorrência está limitada ao norte do alinhamento estrutural do Paranapanema; ela vai perdendo essa feição quando se inflete para oeste, já ao sul do mesmo (FREITAS, 1953). No Estado do Paraná não a encontramos, mas sim um planalto que termina de encontro à escarpa da Serra Geral, constituindo o denominado Segundo Planalto Paranaense (FULFARO, 1974 e 1979).

A depressão portanto limita-se ao norte pelo alinhamento de Araxá-Rio Grande (ASMUS, 1978) e ao sul pelo do Rio Paranapanema (FULFARO, 1974), embora FERREIRA et alii (1981) proponham como limite setentrional do Arco de Ponta Grossa, portanto limite sul da Depressão Periférica, o Alinhamento Estrutural de Guapiara. Está pois a mesma restrita ao compartimento norte da Bacia do Paraná o qual tem apresentado um comportamento menos ascendente que o Arco de Ponta Grossa, ao sul, desde os tempos permocarboníferos. Segundo RAMOS (1970, pág. 90) aí residia a "(depressão deposicional de Taquari) que, durante o Carbonífero Superior, foi inteiramente preenchida, recebendo grande quantidade de sedimentos (Grupo Aquidauana), dominantemente arenosos e de cor vermelha, com espessura superior a 1000 metros".

\subsection{Grandes estruturas do sudeste brasileiro}

$\mathrm{O}$ alto Rio Grande apresenta direção NW paralela aos rios: Tietê, Mo i-Guaçu, do Peixe, Pardo etc. e cujo prolongamento termina no limite norte da Bacia de Santos (região de Cabo Frio). Nesse prolongamento acham-se localizadas as intrusões alcalinas de: Passa Quatro-Itatiaia, Tinguá, Mendanha, Rio Bonito e Morro São João, bem como a depressão da Baía da Guanabara. O litoral do sudeste brasileiro mostra-se afogado entre a Ilha de São Sebastião, ao sul e Cabo Frio, ao norte.

Reforçando o que foi dito, o bloco compartimentado ao sul pelo Alinhamento Estrutural do Paranapanema e ao norte pelo do Rio Grande, este com direção E-W no seu baixo-médio curso e NW no seu alto curso, direção essa finda no continente na região de Cabo Frio, caracteriza um todo mais abatido que o Arco de Ponta Grossa desde o permocarbonífero. Note-se que a bacia tectônica de São Paulo fica no seu limite sul, enquanto que a de Resende fica no seu extremo norte; o semigráben do $\mathrm{Pa}$ raíba do Sul está todo inserido nesse bloco. Note-se também que a espessura dos sedimentos mais derrames na Bacia de Santos é menor nessa porção da plataforma continental do que mais ao sul. 


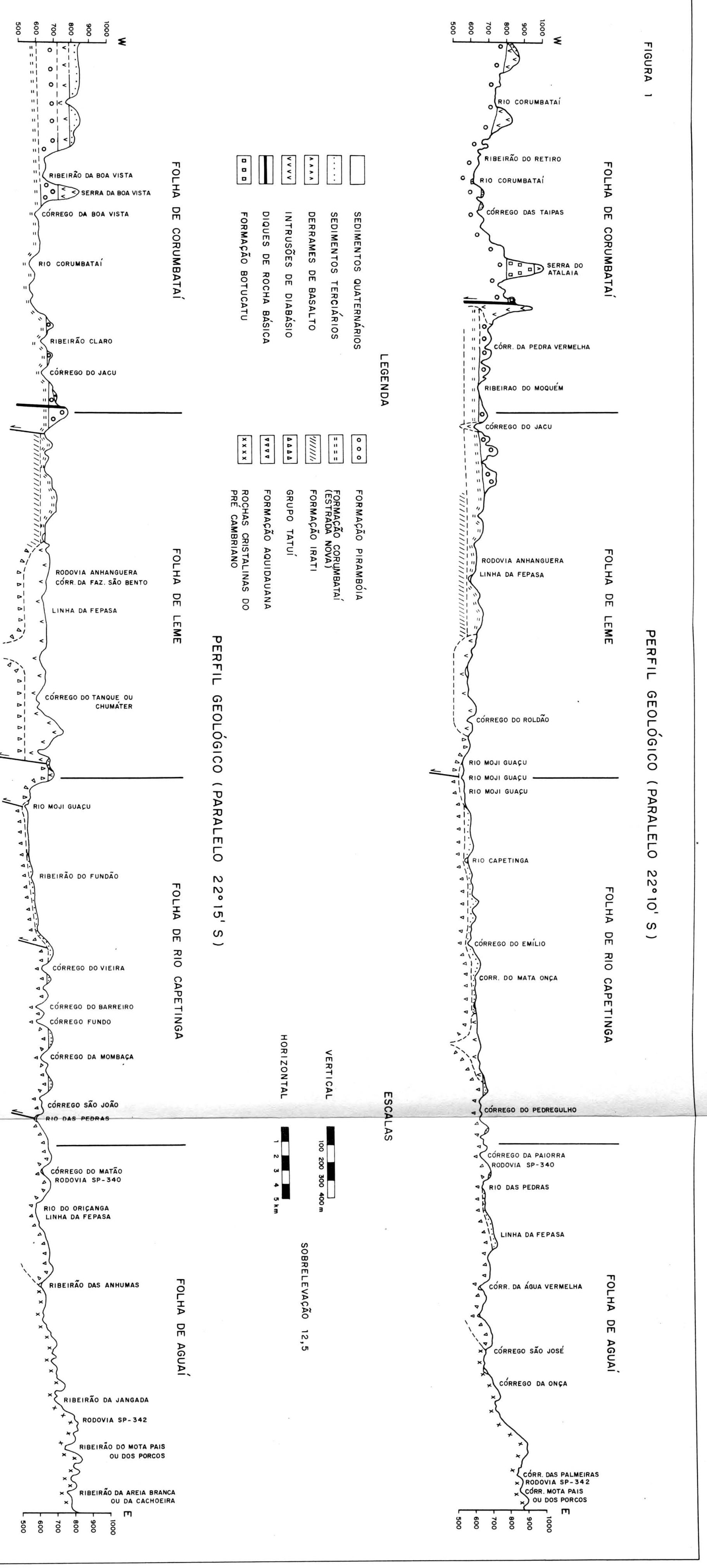


Dois outros fatos são dignos de menção: $10^{\circ}$ - A partir das proximidades do Trópico de Capricórnio para o sul, na área oeste pré-cambriana do Estado, as rochas pertencem ao Proterozóico Superior, em contraposição ao norte, que apresenta unidades do Proterozóico Inferior e Arqueano. Aí, o Grupo São Roque é demarcado pelas falhas de Jundiuvira, ao norte e Taxaquara, ao sul, configurando uma cunha. A partir do Rio Grande para o norte, aparece o Grupo Canastra, do Proterozóico Superior. Desse modo, entre os dois alinhamentos tem-se a ocorrência de rochas mais antigas. Para leste esse arcabouço tectônico-estrutural parece manifestar-se pelas falhas de Taxaquara, Cubatão, Natividade, Bairro Alto, Ribeirão do Ouro, Quinhentos Réis, Camburu, Caraguatatuba etc. $2 .^{\circ}-\mathrm{Na}$ área da Bacia Sedimentar do Paraná, também esse trópico marca o início para o norte de uma região de abundantes intrusões básicas, em contraposição com a região ao sul, onde as mesmas rareiam. Isso indica que a porção hoje deprimida constituiu-se no Juro-Cretáceo em região tectonizada e alimentadora de intrusões magmáticas.

A Serra do Mar, barreira de escarpa de linha de falha, ergue-se próximo à costa com desníveis entre oitocentos e mil metros, que no Rio de Janeiro chegam a alcançar cerca de dois mil e quatrocentos metros. Mais para o interior ergue-se a Serra da Mantiqueira com valores de desnível pouco superiores. Entre ambas existe a depressão alongada, tipo semigráben, caracterizando duas sub-bacias, a de Taubaté, a sudoeste e a de Resende, a nordeste. Logo a sudoeste da Bacia de Taubaté e no mesmo alinhamento geral aparece a Bacia de São Paulo. ASMUS (1981) admite ativo, até épocas mais recentes, o tectonismo responsável por essas feições.

Tomando por base os levantamentos efetuados neste projeto nas folhas de Aguaí, Rio Capetinga, Leme e Corumbataí, foram feitos dois perfis geológicos nos paralelos $22^{\circ} 10^{\prime}$ e $22^{\circ} 15^{\prime} \mathrm{S}$ (Figura 1), cuja interpretação mostra um falhamento de mergulho vertical em escadaria, com as partes mais baixas para oeste, certamente anterior à deposição cenozóica. $\mathrm{O}$ mais importante deles é o localizado no atual terraço do Rio MojiGuaçu, colocando, lado a lado, a Formação Aquidauana (a leste) e o Grupo Tatuí (a oeste), deixando claro que esse rio percorre um alinhamento estrutural. $\mathrm{O}$ aspecto apre- sentado é confirmado por SOARES (1974, pág. 109): "O sistema Descalvado-Santa Cruz da Conceição é formado por falhas com direções entre N2OE e N70W e com bloco baixo para oeste e na maior parte está associada com diques e sills; destes o maior é o de Piraçununga. Os rejeitos são menores que $50 \mathrm{~m}$ ".

\subsection{Tectônica}

Segundo o modelo evolutivo aceito para a margem continental brasileira, data do Cretáceo médio (Aptiano) a formação da crosta oceânica que serve de assoalho ao Atlântico Sul. A partir daí formaram-se fraturas oceânicas 'em continuidade aos alinhamentos continentais, os quais foram então reativados, durante os estágios iniciais da separação Brasil-África, tendo servido de dutos para centros vulcânicos alcalinos no Cretáceo final e Terciário.

O estágio Pré "Rift Valley" de ASMUS \& FERRARI (1978) caracterizou um soerguimento crustal com auge no TriássicoJurássico, nesta porção do sudeste brasileiro, a qual à época, estaria na parte gonduânica hoje limitante Brasil-África. O estágio "Rift Valley" posterior causou uma ruptura da crosta continental, formando bacias tectônicas estreitas, alongadas e profundas, correspondendo à Reativação Wealdeniana de cerca de 130 milhões de anos atrás, com a qual começou a estruturar-se a margem continental brasileira. Os estágios seguintes, Proto-Oceânico e Oceânico, do Aptiano ao Recente causaram espalhamento do piso oceânico, afastando progressivamente o Brasil da África. ASMUS (1975) admite que esse afastamento causaria subsidência da faixa litorânea da crosta, por associar-se também à condição térmica da litosfera, já que o crescimento do assoalho oceânico distanciaria a margem continental da fonte de anomalia térmica, que estaria situada na cadeia meso-oceânica. Com isso haveria uma contração térmica da litosfera, elevação de sua densidade e conseqüente subsidência.

A partir desse início de afastamento e com ápice no Cenozóico constata-se a existência de grande tectonismo causando soerguimento na região continental emersa entre a atual linha de costa e a Bacia Sedimentar do Paraná, desde o Rio de Janeiro até Florianópolis. 
A Reativação Wealdeniana, tendo derramado grande volume de magma na atual Bacia do Paraná e na Bacia de Santos, teria criado profundo desequilíbrio isostático entre essas regiōes e a faixa divisória entre elas, acentuando ainda mais um processo nesse sentido já existente no estágio Pré "Rift Valley" de ASMUS \& FERRARI (1978) e também acrescido pela contínua sedimentação da Bacia do Paraná. Um contínuo afinamento crustal por erosão, nessa região em levantamento teria acelerado o processo. Assim, no Terciário, vencida a resistência das rochas, deu-se uma reativação ao longo de antigas linhas de fraqueza, formando extensos falhamentos.

Conquanto MAACK (1966) e ALMEIDA (1981) apresentem dados maiores para os derrames de lavas na Bacia do Paraná, ficando-se com os números mais modestos de LEINZ (1949) que apresenta um volume de 350 mil quilômetros cúbicos extrudido, não considerando a massa consolidada na forma de diques e "sills" e tomando-se para os basaltos uma densidade igual a 2,9 tem-se que a massa correspondente ao volume extrudido é de cerca de $101,5 \times 10^{13}$ toneladas. A massa média para um prisma de base unitária de um metro quadrado seria de 1015 toneladas (tomando-se uma espessura média de 350 metros para os basaltos).

Pelos números acima expostos pode-se ter idéia da importância dos derrames básicos juro-cretácicos para a tectônica da $\mathrm{Ba}$ cia Intracratônica do Paraná. Imagine-se esse fantástico volume de 350 mil quilômetros cúbicos (não considerados as intrusões e o basalto já erodido) sendo subtraído do Sima, atravessando a parte siálica da crosta $\mathrm{e}$ indo jazer sobre ela. O Sial, cortado de alto a baixo por aberturas tafrogenéticas (geoclases), sentindo seu peso altamente acrescido pelos basaltos e repousando sobre um Sima com perda constante de volume, certamente ficaria instável e o desequilíbrio isostático provocaria a ocorrência de abaixamentos diferenciados, já que os derrames apresentam espessura variável de local para local.

De grande importấncia, embora pouco explorado tectonicamente, é o encontro de conglomerado basal com seixos da Formação Estrada Nova na Formação Itaqueri do Grupo Bauru (ALMEIDA \& BARBOSA, 1953). Esta última formação ocorre na
Folha de Corumbatai (levantamento geológico feito para o mesmo projeto) e folhas adjacentes, a partir da altitude de 900 metros. Entre outros pode ser citado como exemplo o conglomerado ocorrente no quilômetro 138 da rodovia SP-215, que conta com essa contribuição paleozóica. Ora, seixos da Formação Estrada Nova jamais poderiam ser localizados na base do Grupo Bauru, já que as altitudes máximas dessa formação nesta região do Estado não ultrapassam os 800 metros na Folha de Piraçununga, assim, um evento tectônico cenozóico com afundamento da Depressão Periférica poderia justificar esse desnível de cerca de 100 metros. Na já citada Folha de Corumbataí é comum encontrarem-se fālhamentos colocando na mesma cota a Formação Botucatu, derrames de basalto e o Grupo Bauru, o que denota a existência de tal evento. Parece também razoável a hipótese de extensão primitiva maior das formações paleozóicas para leste, o que daria à Formação Estrada Nova altitude suficiente para contribuir para a constituição da parte basal do Grupo Bauru. BJORNBERG et al e FÚLFARO et al apud FULFARO (1974), situam uma possível fonte a nordeste para os sedimentos do Grupo Bauru, inexistindo pois a Depressão Periférica no Cretáceo final. GAMA JÚNIOR (1979, pág. 199) afirma que: "O mapa de tendência de espessuras da fácies Serra Alta sugere que este golfo se estendia além dos atuais limites da borda leste, provavelmente sobre áreas posteriormente anexadas ao continente africano".

A hipótese de primitiva extensão do paleozóico para leste encontra apoio na exi:tência de pequenas "ilhas" da Formação Aquidauana localizadas isoladamente sobre o cristalino a leste da atual borda da Bacia do Paraná (Águas da Prata; norte de Andradas; Véu das Noivas, etc.), encontra apoio também na evolução tectônica proposta para o sudeste do Brasil e especialmente para a Depressão Periférica Paulista, que adota um levantamento do leste no Cenozóico, que certamente acarretaria um levantamento da parte mais externa da bacia, posteriormente erodida.

\section{CONCLUSÃO}

Notam-se pois no contexto desse bloco limitado pelos alinhamentos, do Rio Gran- 
de e do Rio Paranapanema, algumas características típicas que denotam uma evolução tectônica própria:

1 - costa afogada,

2 - bacias de afundimento alinhadas (São Paulo, Taubaté e Resende),

3 - bloco de rochas cristalinas a oeste, de idade mais antiga,

4 - depressão periférica típica na borda da Bacia do Paraná, com abundantes intrusões de diabásio,

5 - profundidade menor do embasamento da Bacia de Santos ao norte da Ilha de São Sebastião, do que ao "sul (ALMEIDA, 1976, fig. 1).

Por outro lado, as idades dos sedimentos mais antigos associados ao processo tectônico exposto mostram contínuo rejuvenescimento para oeste:

\section{Bacia de Santos - Albiano (ASMUS \& FERRARI, 1978)}

Bacia de Taubaté - Oligoceno/Mioceno COUTO \& MEZZALIRA apud ALMEIDA (1976)

Depressão Periférica - (dadas as características de não consolidação, sugere-se idade mais nova, talvez plio-pleistocênica).

Fica proposto aqui um comportamento tectônico caracterizado pelo seguinte: A partir do Cretáceo médio, com o contínuo afastamento dos blocos continentais (BrasilÁfrica) e simultâneo acréscimo do assoalho oceânico, já rompida a crosta do bloco ora em foco, ocorre subsidência da faixa litorânea da mesma, pela falta de suporte rígido do lado leste e pelo acúmulo magmático e sedimentar.

A região oeste adjacente à Bacia de Santos, contendo coluna litosférica menos pesada, permitiu o surgimento de movimentos verticais de levantamento, mais proeminentes no Terciário (NORTHFLEET et alii, 1969; ASMUS; 1975). Esses movimentos opostos criaram falhamentos normais ao longo de direções de fraqueza preexistentes paralelas à costa atual, com deslizamento gravitacional, que determinou o basculamento para oeste de blocos crustais, os quais dẩo atualmente, após as modificações erosivas e deposicionais posteriores, a con- figuração à maneira de cristas das atuais serras, do Mar e Mantiqueira, bem como do Maciço da Carioca, assim também das cavas intermediárias. Esse modelo, aliado à idade dos sedimentos associados, permite admissão de um processo de movimentação contínuo de leste para oeste, passando pela Depressão Periférica e prolongando-se pelo Planalto Ocidental do Estado (FREITAS, 1953) e até para oeste do Rio Paraná, com a maior subsidência das planícies do Chaco Argentino, Paraguaio e Boliviano durante o Pleistoceno (NORTHFLEET et alii, 1965). Essa migração de idades 'dos falhamentos cenozóicos de leste para oeste já fora admitida por ASMUS (1978), LOCZY (1966) estende os movimentos epirogenéticos verticais para toda a Bacia do Paraná.

O exposto significa dizer que a transmissão gradacional da energia para oeste desencadeou uma migração de falhamentos na atual faixa pré-cambriana, os quais tornaram-se progressivamente mais jovens a ocidente. A energização, ao atingir os limites da Bacia Sedimentar do Paraná encontrou aí uma área já deprimida desde o Paleozóico e, pois, sujeita, já de há muito tempo, a um processo compressivo (SOARES, 1974). A reação tectômica foi assim diferente e própria de borda de bảcia intracratônica. O peso dos sedimentos e dos derrames contrapôs-se ao soerguimento de leste, causando disteņ̧ão na bórda, com o que houve afundamento da mesma por, fraturas ao longo de direções de fraqueza do embasamento (COSTA, 1973), com mais acentuados valores para oeste, à medida em que a energização aproximava-se dos densos derrames.

Esse processo de formação da Depressão Periférica é ativo até hoje, apresentando pulsações caracterizadas pelos diferentes ciclos de sedimentação e erosão cenozóicas (FULFARO \& SUGUIO, 1968). Diga-se ademais que ele está ativo em todo o bloco limitado pelos alinhamentos dos rios, Grande e Paranapanema. FULFARO \& PONÇANO, apud FULFARO (1974) descrevem tensões tectônicas residuais na área de Caraguatatuba SOARES (1973) conclui que a tectônica existente na região, nos 'tempos modernos; talvez desde o Cretáceo, seja um movimento epirogenético positivo, muito lento, agindo em impulsos e basculante para oeste. Seria responsável pelas freqüentes retomadas de erosão pelos prin- 
cipais rios, com formação dos diversos níveis de terraços. GONÇALVES (1978) confirma, apresentando como testemunho a existência de superfícies morfológicas tais como níveis aplainados, quebras de gradiente e rampas de declive. PENTEADO (1976) admite como sendo de fins do Terciário e início do Quaternário os falhamentos que deram origem aos morros seccionados e separados do Planalto Ocidental, na Depressão Periférica.

\section{AGRADECIMENTOS}

$\mathrm{O}$ autor expressa seus mais sinceros agradecimentos ao Prof. Dr. Ruy Osório de Freitas pelos seguros ensinamentos quanto à influência da tectônica na formação da Depressão Periférica Paulista; agradece também ao engenheiro Moacyr de Carvalho e à geógrafa Maria Helena de Almeida Mello pelas críticas e sugestões na elaboração do presente trabalho.

\section{REFERENCIAS BIBLIOGRÁFICAS}

ABREU, A.A. - 1973 - Tentativa de compartimentação e estruturação das paisagens do médio vale do Jaguari-Mirim. São Paulo, Universidade, Instituto de Geografia. 24p. (Geomorfologia, 39)

ALMEIDA, F.F.M. de \& BARBOSA, O. - 1953 - Geologia das quadrículas de Piracicaba e Rio Claro, Estado de São Paulo. Rio de Janeiro, DNPM, Divisão de Geologia e Mineralogia. 96p. (Boletim, 143)

- 1976 - The system of continental rifts bordering the Santos basin, Brazil. In: SIMPOSIO INTERNACIONAL SOBRE AS MARGENS CONTINENTAIS DE TIPO ATLÂNTICO, São Paulo, 1975. Anais da Academia Brasileira de Ciências. [Rio de Janeiro] Academia Brasileira de Ciências. Supl. 48:15-26.

1981 - Síntese sobre a tectônica da bacia do Paraná. In: SIMPÓSIO REGIONAL DE GEOLOGIA, 3. , Curitiba. Atas. São Paulo, Sociedade Brasileira de Geologia. v. 1 p. 1-20.

ASMUS, H.E. - 1975 - Controle estrutural da deposição mesozóica nas bacias da margem: continental brasileira. Revista Brasileira de Geociências, São Paulo, 5(3):160-175.

1978 - Hipóteses sobre a origem dos sistemas de zonas de fratura oceânicas; alinhamentos continentais que ocorrem nas regiões sudeste e sul do Brasil. In: PETROBRÁS, RIO DE JANEIRO. CENTRO DE PESQUISAS E DESENVOLVIMENTO. DIVISÃO DE INFORMAÇÃO TÉCNICA E PROPRIEDADE INDUSTRIAL. Aspectos estruturais da margem continental leste e sudeste do Brasil. Rio de Janeiro. p.39-73. (Série Projeto Remac, 4)

\& FERRARI, A.L. - 1978 - Hipótese sobre a causa do tectonismo cenozóico na região sudeste do Brasil. In: PETROBRÁS, RIO DE JANEIRO. CENTRO DE PESQUISAS E DESENVOLVIMENTO. DIVISÃO DE INFORMAÇÃO TÉCNICA E PROPRIEDADE INDUSTRIAL. Aspectos estruturais da margem continental leste e sudeste do Brasil. Rio de Janeiro. p.75-88. (Série Projeto Remac, 4)
ASMUS, H.E. - 1981 - Relacionamento genético de feições geológicas da margem continental sudeste brasileira e da área continental emersa adjacente. In: SIMPÓSIO REGIONAL DE GEOLOGIA, 3. , Curitiba. Atas. São Paulo, Sociedade Brasileira de Geologia. v.1 p.262-273.

BJORNBERG, A.J.S. et alii - 1968a - Nota sobre basculamentos tectônicos no Estado de São Paulo. Ciência e Cultura, São Paulo, 20(2): 160 .

Serra - 1968b- O controle tectônico da 20(2):161.

- - 1971 - Basculamentos tectônicos modernos no Estado de São Paulo. In: CONGRESSO BRASILEIRO DE GEOLOGIA, $25 .^{\circ}$, São Paulo. Anais. São Paulo, Sociedade Brasileira de Geologia. v.2 p.159-174.

BRANDT NETO, M. et alii - 1981 - Sedimentos da Serra de Itaqueri (Formação Bauru e cobertura cenozóica). In: MESA REDONDA: A FORMAÇÃO BAURU NO ESTADO DE SÃO PAULO E REGIÕES ADJACENTES, São Paulo, 1981. Coletânea de trabalhos e debates. São Paulo, Sociedade Brasileira de Geologia. p.63-80. (Publicação, 7)

COSTA, H.F. da - 1973 - Continente Gondwana. Aglutinação, colapso e conseqüências geológicas. Boletim Geográfico, Rio de Janeiro, 32(237):57-70, nov./dez.

FERREIRA, F.J.F. et alii - 1981 - Contribuição ao estudo do alinhamento estrutural de Guapiara. In: SIMPÓSIO REGIONAL DE GEOLOGIA, 3. ${ }^{\circ}$, Curitiba. São Paulo, Sociedade Brasileira de Geologia. v.1 p.226240.

FREITAS, R.O. de - 1953 - Ensaio sobre o relevo tectônico do Brasil. Revista Brasileira de Geografia, Rio de Janeiro, 13(2):171-222.

FÚlFARO, V.J. et alii - 1967 - A tectônica das serras de Santana e São Pedro (Serra Geral). In: CONGRESSO BRASILEIRO DE GEOLOGIA, 21. ${ }^{\circ}$, Curitiba. Anais. São Paulo, Sociedade Brasileira de Geologia. p. 198-205. \& SUGUIO, K. - 1968 - A Formação Rio Claro; Neocenozóico e seu ambiente de deposição. O IGG: Revista do Instituto Geográfico e Geológico, São Paulo, 20(n. ${ }^{\circ}$ único):45-60. 
FULFARO, V.J. - et alü - 1971 - A evolução tectônica e paleogeográfica da bacia sedimentar do Paraná pelo "Trend surface analysi". São Carlos, Escola de Engenharia de São Carlos, USP. 112p. (Geologia, 14).

estrutural 1974 - Tectônica do alinhamento Instituto do Paranapanema. Boletim do te Geociências, USP, 5:129-138.

1979 - O Cenozóico da bacia do Paraná. In: SIMPÓSIO REGIONAL DE GEOlOGIA, 2. ${ }^{\circ}$ Rio Claro. Atas. São Paulo, Sociedade Brasileira de Geologia. v.1 p.231241.

GAMA JUNIOR, E. - 1979 - Sistemas deposicionais do Grupo Passa Dois. In: SIMPÓSIO REGIONAL DE GEOLOGIA, 2. ${ }^{\circ}$, Rio Claro. Atas. São Paulo, Sociedade Brasileira de Geologia. v. 1 p. 195-202.

GONCCALVES, N.M.M. - 1978 - Estudo dos materiais superficiais da região de Ribeirão Preto, SP e suas relações com elementos morfológicos da paisagem. São Paulo. Tese de Mestrado, Instituto de Geociências USP. $177 \mathrm{p}$.

LEINZ, V. - 1949 - Contribuição à geologia dos derrames basálticos do sul do Brasil. São Paulo, Universidade, FFCL. 61p. (Boletim, 103 - Geologia, 5)

LOCZY, L. - 1966 - Evolução paleogeográfica e geotectônica da bacia gondwânica do Paraná e do seu embasamento. Rio de Janeiro, DNPM, Divisão de Geologia e Mineralogia. 71p. (Boletim, 234)

MAACK, R. - 1966 - Os problemas da Terra de Gondwana relacionados ao movimento tangencial de migração da crosta terrestre. Boletim Paranaense de Geografia, Curitiba, (18/20):25-49, out.

MENDES, J.C. \& FÚLFARO, V.J. - 1968 Nova interpretação da tectônica moderna da bacia do Paraná. Ciência e Cultura, São Paulo, 20(2):155.

NORTHFLEET, A.A. et alii - 1969 - Reavaliação dos dados geológicos da bacia do $\mathrm{Pa}$ raná. Boletim Técnico da PETROBRÁS, Rio de Janeiro, 12(3):291-346, jul./ set.

PENTEADO, M.M. - 1968 - Implicações tectônicas na gênese das cuestas da bacia de Rio Claro. Notícia Geomorfológica, Campinas, 8(15):19-41.
PENTEADO, M.M. - 1976 - Geomorfologia do setor centro-ocidental da depressão periférica paulista. São Paulo, Universidade, Instituto de Geografia, 86p. (Série Teses e Monografias, 22).

RAMOS, A.N. - 1970 - Aspectos páleo-estruturais da bacia do Paraná e sua influência na sedimentação. Boletim Técnico da Petrobrás, Rio de Janeiro, 13(3/4):85-93.

RIBEIRO, M.C. - 1973 - Traços de fraturas nas serras de Itaqueri-São Pedro (São Paulo). Ciência e Cultura, São Paulo, Supl. 25(6): 184.

SAAD, A.R. - 1977 - Estratigrafia do Subgrupo Itararé no centro e sul do Estado de São Paulo. São Paulo. Tese de mestrado, Instituto de Geociências USP. 107p.

SANTOS, P.R. - 1979 - Distribuição estratigráfica, características e fácies de diamictitos e rochas associadas do Subgrupo Itararé no centro e sul do Estado de São Paulo. São Paulo. Tese de mestrado, Instituto de Geociências USP. 135p.

SÃO PAULO. INSTITUTO GEOLÓGICO 1980 - Formações geológicas de superfície; folha geológica de Leme [por] Carlos de Carvalho Torres; Geraldo Hideo Oda [e] Percy Corrêa Vieira. São Paulo. Escala 1:50000. (SF-23-Y-A-II-1)

— — 1981 - Formações geológicas de superfície; folha geológica de Rio Capetinga [por] Percy Corrêa Vieira. São Paulo. Escala 1:50000. (SF-23-Y-A-II-2)

- 1982 - Formações geológicas de superfície; folha geológica de Aguaí [por] Geraldo Hideo Oda; Marcos Massoli [e] Carlos de Carvalho Torres. São Paulo. Escala 1:50000. (SF-23-Y-A-III-1) Em preparação para publicação.

— — 1982 — Formações geológicas de superfície; folha geológica de Corumbataî [por] Carlos de Carvalho Torres; Marcos Massoli [e] Lídia Keiko Tominaga. São Paulo. Escala 1:50000. Em preparação para publicação.

SOARES, P.C. - 1973 - Nota sobre a tectônica moderna da depressão periférica paulista. Notícia geomorfológica, Campinas, 13 (25):75-81.

1974 - Elementos estruturais da parte nordeste da bacia do Paraná: classificação e gênese. In: CONGRESSO BRASILEIRO DE GEOLOGIA, 28. ${ }^{\circ}$, Porto Alegre. Anais. Porto Alegre, Sociedade Brasileira de Geologia. v. 4 p. 107-122. 